\title{
Códigos de barras y esencias históricas: una crítica a la versión moderada del esencialismo biológico intrínseco
}

\author{
Barcodes and historical essences: a critique of the moderate version \\ of intrinsic biological essentialism
}

\author{
Julio Torres Meléndez \\ Universidad de Concepción, Chile \\ jutorres@udec.cl
}

\begin{abstract}
Resumen
La actual tendencia a moderar las expectativas de que el código de barras de ADN pueda ser un método de descubrimiento de nuevas especies se debería a que la interpretación esencialista de esta analogía científica es conceptualmente insostenible. Algo semejante ha ocurrido en el campo filosófico con el debilitamiento de las versiones iniciales del esencialismo biológico intrínseco (EBI). Para examinar la naturaleza de esta transición propongo dos principios que definen al EBI moderado: uno que asume que la historia de un taxón es dependiente metafísicamente de la evolución de sus propiedades intrínsecas y, otro, que asume la coextensividad necesaria entre las propiedades intrínsecas que explican el fenotipo de una especie y las propiedades portadoras de las condiciones de identidad de una especie. Argumento que ambos principios son conceptual y empíricamente insatisfactorios.
\end{abstract}

Palabras clave: especies, códigos de barras de ADN, identidad trayecto-dependiente, pleiotropía ecológica/sexual, especiación ecológica.

\begin{abstract}
The current tendency to moderate expectations that DNA barcode can be a method of discovering new species is due to the essentialist interpretation of this scientific analogy that is conceptually unsustainable. Something similar has happened in the philosophical field with the weakening of the initial versions of intrinsic biological essentialism (EBI). To examine the nature of this transition, I propose two principles that define a moderate EBI: one that assumes that the history of the taxon is metaphysically dependent on the evolution
\end{abstract}

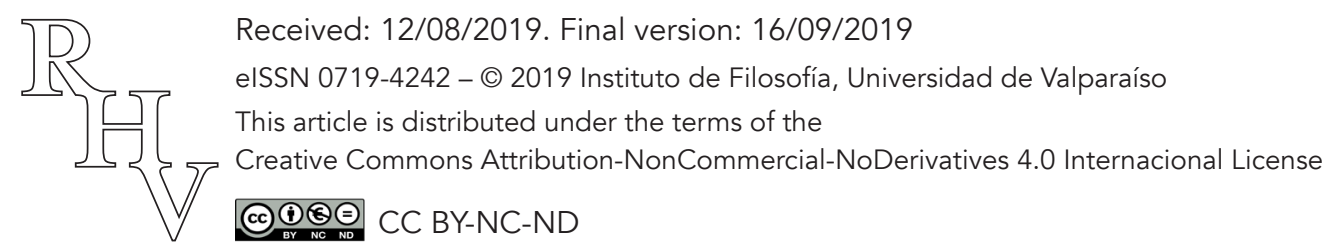


Códigos de barras y esencias históricas: una crítica a la versión moderada del esencialismo biológico intrínseco

Julio Torres Meléndez

of its intrinsic properties and another that assumes the necessary coextensivity between the intrinsic properties that explain the phenotype of the species and the bearers of identity conditions of a species. I argue that both principles are conceptually and empirically unsatisfactory.

Keywords: species, DNA barcodes, path dependence, mating/ecology pleiotropy, ecological speciation.

\section{Introducción}

De acuerdo con el esencialismo biológico intrínseco (EBI), la identidad biológica de las especies reside básicamente en su microestructura genética. La tesis es a la vez metafísica y epistémica. Esas propiedades microestructurales hacen a una individualidad biológica, en un determinado medio, ser lo que es y conocemos su naturaleza esencial conociendo esas propiedades. El EBI es una tesis de metafísicos que es ampliamente rechazada por los filósofos de la biología. Estos han argumentado que la variación genética intrapoblacional y el carácter poblacional de la explicación darwiniana hacen inviable la defensa de esta forma de esencialismo. No habría, según este punto de vista, propiedades genéticas suficientemente estables e invariables para ser candidatas a propiedades esenciales de una especie. Y, de acuerdo con un argumento desarrollado por Elliott Sober, sobre la base de las ideas de Ernst Mayr acerca del carácter no tipológico del pensamiento evolucionista, la explicación de la naturaleza de las especies no requeriría de un compromiso con propiedades esenciales intrínsecas de ningún tipo que compartan los organismos que componen una especie (Sober 1980). La explicación darwiniana es poblacional y antiindividualista: "La población es una entidad sujeta a sus propias fuerzas y que obedece a sus propias leyes" (Sober 1980, 370). El EBI es en cambio fuertemente individualista (Walsh 2006, 440). En defensa del EBI puede argumentarse que el desarrollo de la biología molecular y de los métodos para medir la distancia genética entre poblaciones, sobre la base de secciones mínimas, y suficientemente apropiadas del genoma, conocidas como códigos de barras de $A D N$, han permitido identificar especies a pesar de ese trasfondo de variabilidad genética $\mathrm{y}$, también, han facilitado el descubrimiento de especies crípticas y especies polimórficas. Estos logros objetivos de la biología molecular junto con las representaciones que algunos taxónomos moleculares se han hecho de sus propios métodos parecen, a primera vista, apoyar las convicciones de los esencialistas microestructurales. Es así como en un primer momento los proponentes del método del código de barras de ADN han estado comprometidos también con el EBI. Esto ha ocurrido cuando se ha hecho una interpretación desmesurada de esta analogía entre, por un lado, una determinada sección del genoma mitocondrial de especies animales (el gen citocromo oxidasa subunidad 1) $\mathrm{y}$, por otro, la codificación digital de la identidad universal de un producto comercial o código de barras (Hebert, Stoeckle, Zemlak y Francis 2004). Bajo esta interpretación el

Revista de Humanidades de Valparaíso, 2019, No 14, 75-89

(c) $(1) \Theta(-)$ CC BY-NC-ND 
Códigos de barras y esencias históricas: una crítica a la versión moderada del esencialismo biológico intrínseco

Julio Torres Meléndez

código de barras de ADN contiene en sí mismo la identidad esencial de la especie y esta identidad podría, en principio, ser rápidamente descubierta usando un dispositivo lector portátil como el imaginado en algunas historietas de ciencia ficción. El tricodificador de Star Trek es un buen ejemplo aquí (Holmes 2004).

Pero en la misma comunidad científica comenzó una discusión acerca de los fundamentos conceptuales de este proyecto. Se acusó a los proponentes del código de barras de ADN de confundir los métodos que facilitan la identificación de especies previamente conocidas con los procesos de descubrimiento de nuevas especies (la misión de la taxonomía alfa) (Rubinoff, Cameron y Will 2006). De acuerdo con los taxónomos integrativos, el método del código de barras de ADN no puede ser un método de descubrimiento taxonómico, aunque pueda ser de gran utilidad para identificar muestras fragmentarias, especímenes juveniles y, también, para generar hipótesis, acerca de la existencia de especies no descubiertas, sobre la base de la evidencia de que los códigos de barras de ejemplares desconocidos no concuerdan «con ninguna especie presente en la base de datos de referencia» (Paz, González y Andrew 2011, 163). Es decir, estos métodos moleculares pueden ser utilizados para apoyar hipótesis sobre la base de lo que los filósofos llaman 'inferencias a la mejor explicación' en el contexto de los procesos de descubrimiento. Sin embargo, de acuerdo con el enfoque integrativo, la identidad de las especies se establece por medio de propiedades relacionales tales como el grado de aislamiento reproductivo o las relaciones de ancestro-descendiente (Will, Mishler y Wheeler 2005). Por esta razón es que las hipótesis taxonómicas que puedan generarse a partir del método del código de barras de ADN deben ser testeadas o justificadas usando una pluralidad de propiedades biológicas que estén correlacionadas, por ejemplo, con el grado de aislamiento reproductivo, como ocurre con la diferenciación morfológica, ecológica, etológica y también genética (utilizando una información molecular más amplia que la usada por el código de barras de ADN). Estas propiedades biológicas permiten contrastar hipótesis acerca de la existencia de una comunidad aislada reproductivamente o acerca de la existencia de determinadas relaciones filogenéticas, pero ellas no constituyen un criterio de especie. Cuando, por ejemplo, no hay evidencia directa acerca del grado de aislamiento reproductivo, el taxónomo usa esas propiedades, que en su teoría proporcionan una información conceptualmente independiente de su criterio de especie (es decir, de la manera en que se define la categoría de especie), como indicadores inductivamente correlacionados con el aislamiento reproductivo para contrastar sus hipótesis o propone una determinada hipótesis acerca del grado de aislamiento reproductivo como la mejor explicación de la evidencia disponible. Pero en la interpretación desmesurada de la analogía del código de barras de $\mathrm{ADN}$, se trata a la evidencia molecular como un criterio de especie y, por esto, no pueden existir, en principio, propiedades independientes de la evidencia molecular que pueda confirmar o refutar una hipótesis taxonómica de este tipo. El problema se muestra en poblaciones estrechamente relacionadas. No es aquí posible determinar, en principio, solo con la evidencia molecular, qué valor de distancia genética

Revista de Humanidades de Valparaíso, 2019, No 14, 75-89 
Códigos de barras y esencias históricas: una crítica a la versión moderada del esencialismo biológico intrínseco

Julio Torres Meléndez

se corresponde con una distinción real, no meramente convencional, entre poblaciones (Lee 2004, 2). El método del código de barras de ADN como método de descubrimiento aparece ilusoriamente plausible cuando se comparan especies distantes filogenéticamente, pero en estos casos la evidencia morfológica y etológica ha proporcionado desde siempre la información requerida como lo muestra el alto grado de coincidencia entre las identificaciones vernáculas y científicas de los taxa a nivel de especie (Mayr 1968, 33). No ocurre así entre poblaciones recientemente escindidas de un ancestro común.

Pero todo indica que las interpretaciones esencialistas de este método han quedado superadas a pesar del entusiasmo inicial y, también, del intento de equiparar sus problemas en el descubrimiento de especies a las dificultades empíricas que son comunes a la aplicación de los diversos conceptos de especie que se apoyan en propiedades biológicas relacionales (véase al respecto las afirmaciones que hace Paul Hebert en Holmes 2004, 34). Es probable que se haya advertido que las dificultades del código de barras de ADN, como he mostrado, son más bien conceptuales y esto explicaría que se aluda ahora a su importancia de una manera claramente instrumental para los fines de la taxonomía integrativa. Su utilidad en el descubrimiento radicaría "especialmente en grupos poco estudiados, ya que puede filtrar rápidamente las colecciones de especies presuntas, para que entonces puedan ser objeto de estudio taxonómico" (Hebert, Hollingsworth y Hajibabaei 2016, 5). El código de barras de ADN es visto apropiadamente como un recurso para iniciar aceleradamente el trabajo taxonómico, pero no como un método que por sí mismo resuelva los problemas del descubrimiento de nuevas especies (Kekkonen y Hebert 2014).

Paralelamente, en el campo filosófico, las versiones moderadas del EBI parecen también corregir sus posiciones anteriores a la luz de las críticas recibidas. Un síntoma de esto es que sus proponentes han integrado propiedades históricas y relacionales a sus definiciones intrínsecas de la categoría de especie y de jerarquías taxonómicas superiores. Como veremos la manera en que se produce esta integración de la historia y de otras propiedades relacionales reviste cierta complejidad en el contexto del EBI y no estará libre de problemas conceptuales y de inconsistencias con los logros de la investigación empírica. Las interpretaciones moderadas del código de barras de ADN que integran criterios históricos o relacionales a su definición de la categoría de especie deben ser entendidas también como versiones moderadas del EBI y los problemas conceptuales y empíricos de estas versiones moderadas deberían reproducirse también en las interpretaciones moderadas del código de barras de ADN, aunque no abordaré esta cuestión aquí. Me propongo entonces identificar la naturaleza conceptual de la transición desde las concepciones iniciales o tradicionales del EBI hacia la versión moderada, para argumentar en contra de lo que considero una concepción insatisfactoria, desde el punto de vista evolutivo, del componente histórico que se incorpora al EBI como parte de la esencia

Revista de Humanidades de Valparaíso, 2019, No 14, 75-89

(c) $(1)(9)$ CC BY-NC-ND 
Códigos de barras y esencias históricas: una crítica a la versión moderada del esencialismo biológico intrínseco

Julio Torres Meléndez

de un taxón. Finalmente, muestro que hay también razones empíricas, provenientes de un caso de especiación ecológica en murciélagos, para dudar acerca de lo que propondré son algunos de los principios centrales del EBI.

\section{Historia y roles constitutivos}

De acuerdo con EBI, ¿qué relevancia tiene la historia en el descubrimiento de la esencia de un taxón? Considérese, en primer lugar, la distinción entre propiedades constitutivas y propiedades que originan o causan esas propiedades constitutivas, que introduce Travis Dumsday en el contexto de esta discusión. De acuerdo con Dumsday, propiedades relacionales, tales como ocupar un determinado nicho ecológico, pueden causar que una determinada población tenga una determinada identidad intrínseca, pero esa propiedad relacional no es constitutiva de tal identidad (Dumsday 2012, 499). Dumsday separa aquí las propiedades constituyentes de la identidad de una especie de las propiedades que los diversos modelos de especiación identifican para explicar el origen de las especies. Y algo similar había sostenido previamente Michael Devitt. De acuerdo con Devitt, la cuestión central del EBI es qué mecanismo, independientemente de cuál sea su origen, explica ahora la verdad de las generalizaciones acerca de los taxa (Devitt 2008, 352). Devitt hace esta distinción usando los conceptos de explicación estructural y explicación histórica de Philip Kitcher (2003 [1984], 121). Una explicación estructural nos permite hacer generalizaciones acerca de las propiedades fenotípicas de un organismo que se apoyan en la existencia de determinados mecanismos microestructurales (propiedades genéticas y procesos de desarrollo celular). La explicación histórica, en cambio, "nos dice cómo los miembros de un taxón llegan a tener estos mecanismos" (Devitt 2018a, 8; Devitt 2008, 353). El concepto de explicación estructural tiene aquí la ventaja de mostrar con mayor claridad que las esencias que postula el proponente del EBI cumplen un doble rol: dan cuenta de la identidad de un organismo y, también, explican causalmente sus propiedades fenotípicas por medio de propiedades intrínsecas o microestructurales. De acuerdo con Devitt, "la esencia intrínseca" es un mecanismo causal que hace de un determinado organismo lo que organismo es y explica la manera en que lo es (Devitt 2018a, 10). Llamaré 'propiedades constitutivas' a las propiedades intrínsecas que cumplen este rol tanto individualizador como causal y cuyo origen es, en este contexto, irrelevante. Las clases naturales de la teoría química son, por cierto, el paradigma de esa separación entre propiedades constitutivas y propiedades históricas. El proceso, natural o no, que causó que una determinada molécula sea la que es, por ejemplo, una molécula de agua, no es parte de las propiedades constitutivas del agua. Dondequiera que se ejemplifiquen esas propiedades constitutivas habrá agua y, por tanto, el origen o la historia que explica la instanciación de esas propiedades es irrelevante para la determinación de su naturaleza. Las clases naturales de la química son también el paradigma de la concatenación del doble rol que cumplen esas propiedades constitutivas: proporcionan la identidad de cada clase y explican causalmente sus propiedades físico-químicas. Las especies biológicas

Revista de Humanidades de Valparaíso, 2019, No 14, 75-89

(c) $(1) \Theta(-)$ CC BY-NC-ND 
Códigos de barras y esencias históricas: una crítica a la versión moderada del esencialismo biológico intrínseco

Julio Torres Meléndez

reproducen, de acuerdo con el EBI, por un lado, este mismo patrón de división entre origen y constitución; y, por otro, reproducen también la coincidencia extensional entre propiedades responsables de la individuación y propiedades que proporcionan explicación estructural. Expresaré estas tesis, respectivamente, como formas de compromiso con dos principios:

Principio de irrelevancia del origen: la historia evolutiva de un taxón no cumple ningún rol constitutivo.

Principio de coextensividad de los roles constitutivos: las propiedades intrínsecas que causan en un determinado medio el fenotipo de un taxón son también sus propiedades individualizadoras.

Sin embargo, a pesar de su insistencia inicial respecto de que los procesos causales que originan una especie no son constitutivos de su identidad, Dumsday afirmó recientemente que las propiedades intrínsecas del genoma de una especie no permiten, por sí mismas, la determinación de su identidad. Según este punto de vista es una condición necesaria pero no suficiente de la identidad de una especie el que ella tenga tal propiedad microestructural. Para determinar su identidad debemos obtener también información acerca de su ubicación en un determinado linaje o línea de descendencia (Dumsday 2017, 606; Dumsday 2012, 499). Dumsday hace una distinción aquí entre una versión tradicional del EBI y una versión moderada. La versión moderada, a primera vista, parece abandonar por completo el Principio de irrelevancia del origen y conservar el Principio de coextensividad de los roles constitutivos. Dumsday rechaza de esta manera el esencialismo tipológico: las especies no son tipos o géneros naturales que conserven su identidad donde quiera que se instancie una determinada microestructura genética. La propiedad relacional de pertenecer a determinado linaje tiene ahora, parcialmente, un rol constitutivo respecto de la identidad. Esta tesis es asumida también por Devitt quien sostiene "que hay, al menos, un componente histórico" en la esencia de cada taxón (Devitt 2018a, 5), aunque, como veremos, no abandona su anterior idea según la cual las propiedades intrínsecas tienen prioridad causal respecto de las propiedades relacionales tal como el aislamiento reproductivo (la propiedad relacional que utiliza en Concepto Biológico de Especie como el criterio de especie). Esta prioridad causal del componente intrínseco la encontramos también respecto de las propiedades históricas o filogenéticas. De acuerdo con Devitt, el error del esencialismo estrictamente histórico fue olvidar "la dependencia del componente histórico" respecto del componente intrínseco (Devitt 2018b, 1). La tesis esencialista de Samir Okasha es representativa de este punto de vista que ataca Devitt. Okasha afirma que las especies tienen propiedades relacionales esenciales (como el aislamiento reproductivo o la relación ancestro-descendiente), pero al mismo tiempo rechaza la idea de que ellas tengan propiedades intrínsecas esenciales. Por ejemplo, desde el punto de vista de un concepto filogenético de especie, la propiedad que cumple el rol individualizador de una especie la constituye la propiedad esencial de "pertenecer a un particular segmento del

Revista de Humanidades de Valparaíso, 2019, No 14, 75-89

(c) $(1)(9)$ CC BY-NC-ND 
Códigos de barras y esencias históricas: una crítica a la versión moderada del esencialismo biológico intrínseco

Julio Torres Meléndez

nexo genealógico" (Okasha 2002, 202). No hay razones a priori, afirma Okasha, para que una propiedad esencial relacional tenga tanto una función causal como una función semántica o individualizadora (Okasha 2002, 203). En la sistemática filogenética esas propiedades relacionales cumplen, según Okasha, la función semántica pero no la causal y lo mismo debería afirmarse respecto de otras propiedades que utilizan los distintos conceptos relacionales especie para determinar la identidad de un taxón.

Devitt rechaza esa forma débil de esencialismo porque, entre otras razones, una esencia estrictamente histórica, esto es, sin componente intrínseco, carece de poder causal y por ello no sería capaz de producir explicaciones estructurales (una tesis que Devitt comparte con Okasha). Devitt asume que una propuesta genuinamente esencialista debe proporcionar no solo un criterio de identidad sino también una explicación causal de las propiedades estructurales de un género natural (Tahko 2015 y Ereshefsky 2010b). Un esencialismo histórico sin componente microestructural no cumpliría ninguno de estos roles constitutivos. Sería, por sí mismo, incapaz de proporcionar criterios de identidad para dos especies que se han escindido de una especie ancestral. Si las especies B y $\mathrm{C}$ se han escindido de la especie ancestral $\mathrm{A}$, ¿cómo podríamos distinguir entre $\mathrm{B}$ y $\mathrm{C}$ sin criterios intrínsecos? La individuación en términos históricos no podría, de acuerdo con Devitt, hacer esta distinción. Entonces no cualquier historia cuenta como parte del componente histórico de la esencia de las especies. La clase de historia que es esencial a un organismo, dice Devitt, es aquella en donde un determinado tipo intrínseco evoluciona hacia otro determinado tipo intrínseco (Devitt 2018a, 14). En Devitt 2018b se sostiene asimismo: "la historia relevante de un taxón $\mathrm{T}$ es aquella en donde los organismos de un tipo evolucionan a organismos de otro tipo [...]" (p. 6). La versión moderada del EBI abandonada solo parcialmente la idea según la cual la historia es irrelevante para la determinación de la identidad, es decir, el EBI moderado abandona el Principio de irrelevancia de origen propiamente tal, para reemplazarlo por una versión restringida que puede expresarse de la siguiente manera:

Principio restringido de irrelevancia del origen: la historia de un taxón que tiene un rol constitutivo para su identidad es la historia dependiente metafísicamente de la evolución de las propiedades intrínsecas de los organismos de ese taxón.

Devitt expresa este principio también bajo la idea de que la esencia intrínseca de un organismo implica su componente histórico. De esto se sigue también la tesis de que los organismos pertenecen esencialmente a su taxón. Un organismo $\mathrm{O}$ es esencialmente un miembro de un taxón $\mathrm{T}$, si y solo si, la esencia de $\mathrm{O}$ entraña la esencia de su taxón $\mathrm{T}$ (Devitt 2018a, 2) ${ }^{1}$. Pero, como veremos, este principio deja parte importante de la historia de un taxón fuera del alcance individualizador y también causal que tienen, para el EBI, las propiedades intrínsecas.

${ }^{1}$ La formulación original es " $\mathrm{O}$ is essentially a member of $\mathrm{T}$ iff its having Eo entails its having Et".

Revista de Humanidades de Valparaíso, 2019, No 14, 75-89

(c) $(1)(9)$ CC BY-NC-ND 
Códigos de barras y esencias históricas: una crítica a la versión moderada del esencialismo biológico intrínseco

Julio Torres Meléndez

\section{La historia à la Devitt no es historia evolutiva}

Podemos ahora enunciar el problema central de la tesis según la cual los taxa tienen un componente histórico dependiente de su componente intrínseco esencial: de acuerdo con esta tesis la historia de un taxón sobreviene a la evolución de las propiedades intrínsecas de sus organismos ${ }^{2}$. Pero esta idea es extraña al pensamiento evolucionista y parece más bien un retroceso hacia una explicación estructuralista pre-darwiniana de la forma biológica, al otorgar prioridad causal exclusiva a las propiedades intrínsecas de los taxa y no a las contingencias históricas que explican gran parte del patrón de sus adaptaciones. En favor de este principio está el hecho de que las propiedades intrínsecas condicionan tanto negativamente como positivamente la evolución. Este es el sentido que S. J. Gould le da a la constricción interna o estructural como "impedimento o límite al poder de la selección natural", pero también "como promotor, suministrador o causa de la dirección del cambio evolutivo" (Gould 2004 [2002], 1057). Hay evidencia experimental al respecto. El microbiólogo Richard Lenski lideró en 1988 un experimento evolucionista de larga duración con doce poblaciones bacterianas genéticamente idénticas y sometidas también a idénticas presiones ambientales (experimento conocido como Long-term Experimental Evolution o LTEE). Los doce linajes han evolucionado divergentemente durante más de 65.000 generaciones (al año 2016) y se han diferenciado en relación a su volumen celular y a su aptitud relativa a pesar de que les ocurrieran, con excepciones, una acumulación de las mismas mutaciones favorables en los mismos genes (aunque raramente idénticas a nivel de nucleótidos) (Blount, Lensky y Losos 2018). Aunque estas mutaciones les permitieron, en general, la adaptación a los mismos desafíos ecológicos, ellas surgieron, presumiblemente, en un orden temporal distinto, lo que explica la divergencia de la historia evolutiva. La secuencia en que surgen las mutaciones es relevante también para que la selección acumulativa produzca tales o cuales fenotipos. Esta es una forma de historicidad que, de acuerdo con Eric Desjardins, se expresa tanto en la dependencia del proceso evolutivo respecto de las condiciones iniciales intrínsecas como también en la dependencia de la trayectoria [path dependence], es decir, en el hecho de que la probabilidad de que un determinado resultado pueda cambiar si se toma, entre distintas alternativas posibles, una determinada trayectoria y no otra (Desjardins 2011, 353). Esto es justamente lo que ocurre cuando el orden de las mutaciones es determinante para que solo en una de las poblaciones bacterianas del LTEE evolucionara la capacidad de crecer aeróbicamente en citrato (Cit+) (Blount, Lensky y Losos 2018, 4). El LTEE confirma la tesis moderada del EBI: las doce poblaciones bacterianas tienen una historia evolutiva que es el resultado de la interacción entre la naturaleza intrínseca de los organismos y el medio, pero no hay cambios en esa historia evolutiva que no estén acompañados por cambios intrínsecos y cada diferencia entre las distintas poblaciones es dependiente exclusivamente de la evolución de las propiedades intrínsecas de cada una de ella a

${ }^{2}$ Acerca del concepto de superveniencia invocado aquí, cf. Kim (2003[1993]) y García-Carpìntero (1996).

Revista de Humanidades de Valparaíso, 2019, No 14, 75-89

(c) $(9)(9)$ CC BY-NC-ND 
Códigos de barras y esencias históricas: una crítica a la versión moderada del esencialismo biológico intrínseco

Julio Torres Meléndez

partir de un estado inicial común. Sometidas a las mismas presiones ambientales, y a partir de las mismas condiciones iniciales, la diferencia en la historia evolutiva solo puede ser explicada por la existencia de una diversidad de alternativas posibles y por la dinámica contingente de la acumulación de mutaciones favorables que toman una u otra de esas alternativas. No ocurre lo mismo, sin embargo, en los eucariotas pluricelulares de reproducción sexual. El LTEE ha servido tanto para contrastar hipótesis científicas acerca del carácter contingente, impredecible e irreversible de la evolución como también para el examen filosófico de la naturaleza y la relevancia de la historia en la explicación evolucionista, pero sus resultados no son completamente simétricos respecto de cómo la dependencia de la trayectoria afecta la identidad de los taxa pluricelulares altamente integrados y en donde también hay un alto grado de división entre células somáticas y células germinales (Godfrey-Smith 2009). Esto no es sorprendente dado que el surgimiento de una individualidad darwiniana pluricelular representa, como se ha sostenido, una de las mayores transiciones evolutivas (Maynard Smith y Szathmary 1995; Veit 2019). Si en estos taxa la contingencia histórica puede comenzar antes de que exista una evolución de las propiedades intrínsecas de sus individuos y, por esta misma razón, puede, posteriormente, de manera retrospectiva, condicionar su identidad, entonces el Principio restringido de irrelevancia del origen no representa correctamente la historicidad de la evolución. Al menos, no de las poblaciones cuyos individuos se reproducen sexualmente y en donde consecuentemente los procesos de especiación suponen el surgimiento de barreras que impiden el intercambio génico entre estas poblaciones. La idea de que podemos prescindir de la historia biológica que no dependa de la evolución de las propiedades intrínsecas, tal como se expresa en el Principio restringido de irrelevancia de origen, es inconsistente con la identidad trayecto-dependiente que suponen los distintos modelos de especiación. De la dependencia metafísica que establece el Principio restringido de irrelevancia del origen entre la historia y la evolución de las propiedades intrínsecas, se sigue que debe haber diferencia intrínseca para que dos organismos que pertenezcan a taxones distintos entrañen un componente histórico distinto. Si no hay diferencia intrínseca entre dos taxones recientemente escindidos de una especie ancestral, entonces este entrañamiento no podría ser sino mágico. ¿Por qué estaría entrañando un determinado taxón y no el otro? Pero debe advertirse que el punto de origen de una especie radica en el punto de división o ramificación de una especie ancestral. Considérese que en el modelo alopátrico de especiación no es posible determinar que el aislamiento geográfico de una población escindida de una especie ancestral constituya el origen de una nueva especie si no conocemos el resto de la historia de la especie. No se trata aquí solo de una contingencia epistémica, una cuestión relativa a la imposibilidad de conocer esa historia o al menos de conocerla con precisión, sino de una indeterminación ontológica que solo se resuelve retrospectivamente. Solo retrospectivamente podemos determinar que ese proceso de división dio origen a una nueva especie. Las especies son entidades cuya naturaleza es dependiente de la historia de una manera singular: su entidad no solo está condicionada por el estado inicial, sino que también por lo que sucederá en el futuro

Revista de Humanidades de Valparaíso, 2019, No 14, 75-89

(c) $(9)(9)$ CC BY-NC-ND 
Códigos de barras y esencias históricas: una crítica a la versión moderada del esencialismo biológico intrínseco

Julio Torres Meléndez

como lo ha argumentado Marc Ereshefsky (Ereshefsky 2014, 720). Aunque la evolución bacteriana parece confirmar el Principio restringido de irrelevancia de origen, los taxa pluricelulares altamente integrados no lo hacen.

\section{Pleiotropía ecológica/sexual y el Principio de coextensividad de los roles constitutivos}

En lo que sigue consideraré un ejemplo de especiación ecológica en murciélagos que refuta el Principio de coextensividad de los roles constitutivos. Como veremos, si no hay coextensividad en el sentido requerido por EBI, pierde justificación tanto la tesis según la cual los organismos entrañan el componente histórico del taxón al que pertenecen como la tesis de que su pertenencia es necesaria. Consideremos el caso del murciélago herradura (Rhinolophus philippinensis). Los biólogos Tigga Kingston y Stephen Rossiter han identificado tres morfos caracterizados por tres tamaños, cuyo rango de largo de brazo va, aproximadamente, de 47 a $56 \mathrm{~mm}$ (grandes, intermedios y pequeños) (Kingston y Rossiter 2004). Estos morfos están aislados reproductivamente presumiblemente debido a su diferencia en la frecuencia de llamada de ecolocalización. Los grandes emiten llamados de baja frecuencia, cuya gran amplitud de onda permite la captura de insectos grandes, aunque son funcionalmente sordos a los pequeños. Los medianos emiten llamados de frecuencia intermedia que permite la captura de insectos de talla media. Los de tamaño pequeño emiten llamadas de alta frecuencia que les permite solo atrapar presas de menor tamaño, y son, por ello, sordos a los insectos grandes. Dado que las llamadas de ecolocalización permiten también la comunicación y el reconocimiento sexual, las presiones ecológicas pueden resultar disruptivas y eliminar los morfos intermedios produciendo, al mismo tiempo, aislamiento reproductivo entre estas poblaciones. De ahí que la llamada de ecolocalización constituya un ejemplo de 'rasgo mágico' (Gavrilets 2004, 368) o de 'pleiotropía ecológica/sexual' [mating/ecology pleiotropy] (Bolnick y Fitzpatrick 2007, 470). Un rasgo de este tipo tiene la peculiaridad de realizar una doble función (una relativa a sus interacciones ecológicas y otra de reconocimiento sexual). Estas dos funciones generalmente residen en rasgos distintos, pero en este caso ellas coinciden extensionalmente en un solo rasgo controlado por un solo conjunto de genes (Nosil 2012, 34; Servedio et al. 2011, 389).

Kingston y Rossiter sostienen que el origen de los saltos armónicos es un problema no resuelto en sus aspectos fisiológicos, aunque se presume que se debe a cambios en la estructura del sistema auditivo (la dimensión de la cóclea), un sistema que está estrechamente relacionado con la afinación de la frecuencia de ecolocalización (Kingston y Rossiter 2004). Para los presentes propósitos asumiré simplemente que los saltos armónicos constituyen un acervo de variabilidad fenotípica, generada por mutación y recombinación, que tiene una distribución normal en la población cuando no hay presiones

Revista de Humanidades de Valparaíso, 2019, No 14, 75-89

(c) $(1)(9)$ CC BY-NC-ND 
Códigos de barras y esencias históricas: una crítica a la versión moderada del esencialismo biológico intrínseco

Julio Torres Meléndez

ecológicas que provoquen adaptación disruptiva o divergente. Así fue interpretado hipotéticamente por Gareth Jones y Sofie Van Parijs para el caso de la distribución bimodal de las frecuencias de llamado que detectaron en los murciélagos Pipistrellus pipistrellus:

Una distribución normal de las frecuencias de llamada puede ser dividida en una distribución bimodal por la selección disruptiva. Si esto ocurrió así y los murciélagos con similares frecuencias tendieron a agregarse en colonias, nuevas especies pudieron formarse en la misma área geográfica. [...] La competición entre los extremos podría ser menor que la que hay entre los intermedios y la frecuencia puede divergir. (Jones y Van Parijs 1993, 124)

Aunque, al parecer, no es este el punto de vista de Kingston y Rossiter. Ellos sostienen que:

[...] si asumimos que la comunicación acústica es importante para el reconocimiento de pareja, como típicamente ocurre en los murciélagos, los saltos armónicos pueden proveer de un mecanismo intrínseco de aislamiento precopulatorio instantáneo [instantaneous premating isolation]. (Kingston y Rossiter 2004, 655)

Pero esta afirmación no es consistente con el modelo ecológico de especiación que ellos mismos asumen cuando afirman que la "selección ecológica divergente" podría producir aislamiento reproductivo, si el rasgo bajo selección puede influir en el reconocimiento de pareja y tiene como resultado la segregación de cruzamiento (Kingston y Rossiter 2004, 655). No hay tal mecanismo intrínseco de aislamiento instantáneo, dado que los saltos armónicos podrían mantenerse y propagarse en la población sin producir aislamiento si no hay presiones ecológicas disruptivas sobre ella. Aquí, como en las especies anillo, el flujo génico interespecífico podría ser posible a través de los morfos intermedios (Ereshefsky 2010b, 681). De hecho, Kingston y Rossiter detectaron alguna evidencia al respecto:

Los grandes y pequeños morfos son [...] funcionalmente sordos a otras llamadas de frecuencia-constante. Aunque los morfos intermedios podrían ser capaces de oír las frecuencias usadas por los grandes morfos, y pueden ser oídos por los morfos pequeños, en ningún caso esta receptividad es recíproca (Kingston y Rossiter 2004, 655).

También admiten que es muy posible que la población ancestral haya contenido más diversidad genética que la que actualmente conocemos (Kingston y Rossiter 2004, 655). Esto puede ser un indicio de que la selección disruptiva eliminó una parte importante de los morfos intermedios que hacían posible la percepción recíproca de las señales de ecolocalización y que en el pasado pudo haber permitido el flujo génico en toda la población. Esta interpretación haría consistentes los resultados empíricos con el modelo ecológico de especiación, aunque subsiste un problema. Las diferencias de frecuencia encontradas corresponden a saltos armónicos sobre la base de una frecuencia fundamental. Las frecuencias de llamado de los distintos morfos son efectivamente múltiplos de esa frecuencia fundamental. Las frecuencias intermedias respecto de los armónicos son

Revista de Humanidades de Valparaíso, 2019, No 14, 75-89

(c) $(1)(9)$ CC BY-NC-ND 
Códigos de barras y esencias históricas: una crítica a la versión moderada del esencialismo biológico intrínseco

Julio Torres Meléndez

físicamente posibles, pero probablemente tendrían muy poco valor para la sobrevivencia. Quizás esta sea la razón por la cual para Kingston y Rossiter los saltos armónicos constituyen un mecanismo intrínseco de aislamiento reproductivo instantáneo.

La coincidencia extensional en los rasgos mágicos entre, por un lado, determinada propiedad que cumple una función adaptativa y, por otro, una propiedad de reconocimiento sexual, parece, a primera vista, respaldar el Principio de coextensividad de los roles constitutivos. Efectivamente, los genes que causan la llamada ecolocalización son también los genes que causan las señales de reconocimiento sexual que dan origen al aislamiento reproductivo y que determinan la identidad biológica de la población. Pero debe advertirse que es parte del concepto de rasgo mágico el que se trate de un rasgo sometido a selección divergente tal como se muestra en la incipiente especiación ecológica de $R$. philippinensis. Antes de que hubiera selección divergente, la pleiotropía ecológico/sexual estaba presente pero no generó aislamiento reproductivo. La magia (como siempre) es una ilusión: la pleiotropía ecológico/sexual propia de los rasgos mágicos no produce, como hemos visto, especiación instantánea o automática. Se requiere también selección divergente que elimine los fenotipos intermedios por su menor eficacia biológica respecto de los fenotipos extremos en la distribución normal de la población original (Soler 2003, 139). La coextensividad de los roles constitutivos que requiere, en cambio, el EBI, es incondicionada e individualista. Sus principio de identidad no depende de ninguna propiedad relacional y poblacional tal como el grado de aislamiento reproductivo, sino simplemente de las propiedades intrínsecas del genoma del individuo. Este y otros casos de especiación ecológica muestran que el Principio de coextensividad de los roles constitutivos es falso y con ello también lo es la tesis según la cual los organismos entrañan el componente histórico del taxón al que pertenecen. No puede haber tal entrañamiento, pues antes y después del proceso de especiación ecológica, las propiedades intrínsecas son exactamente las mismas para los individuos de la población ancestral y para los individuos que pasan a integrar poblaciones aisladas reproductivamente luego de la acción de la selección divergente que elimina los morfos intermedios. La historia del taxón se ha escindido, pero esta historia no es dependiente de la evolución de las propiedades intrínsecas de los individuos. Aquí la historia no superviene en las propiedades genómicas de los individuos, dado que estas propiedades no han cambiado a pesar de la divergencia histórica de estas dos poblaciones. Y los organismos tampoco pertenecen de manera necesaria al taxón al que pertenecen: su pertenencia es obviamente contingente, está condicionada a la contingencia de la selección divergente.

\section{Conclusiones}

He mostrado que tanto las interpretaciones esencialistas del código de barras de ADN, como las versiones tradiciones del EBI, han moderado sus posiciones integrando propiedades relacionales e históricas a sus criterios inicialmente puramente intrínsecos

Revista de Humanidades de Valparaíso, 2019, No 14, 75-89

(c) $(i) \Theta(9)$ CC BY-NC-ND 
Códigos de barras y esencias históricas: una crítica a la versión moderada del esencialismo biológico intrínseco

Julio Torres Meléndez

para delimitar especies. Las interpretaciones desmesuradas del código de barras de ADN son inviables por razones conceptuales y no, como lo han supuesto algunos taxónomos integrativos, por razones meramente empíricas. Respecto de la versión moderada del EBI, he propuesto dos principios que pretenden definirla: el Principio restringido de irrelevancia del origen y el Principio de coextensividad de los roles constitutivos. El primero es refutado por la identidad trayecto-dependiente que es propia de la naturaleza histórica de los procesos evolutivos de los organismos multicelulares altamente integrados. La identidad dependiente de la trayectoria no requiere que la historia sobrevenga a las propiedades genéticas de los individuos como se muestra en el proceso de especiación ecológica que divide a $R$. philippinensis en dos poblaciones aisladas reproductivamente. Las propiedades genéticas de los organismos individuales deberían aquí, por sí mismas, entrañar su componente histórico como requiere el EBI moderado. Pero esta noción de entrañamiento carece de sentido en el contexto de los modelos ecológicos de especiación. Estos modelos suponen que la diferencia genética que va a caracterizar a ambas poblaciones debe estar previamente distribuida en los extremos de la curva normal de la frecuencia de la variación genética de la población y, por esta razón, esta variación existe en los organismos individuales antes del proceso de especiación por selección divergente. La historia evolutiva de ambas poblaciones cuyo ancestro común es $R$. philippinensis no es entonces dependiente metafísicamente de la evolución de las propiedades intrínsecas de sus organismos componentes. Este ejemplo de especiación refuta también el Principio de coextensividad de los roles constitutivos. No hay tal coextensividad a pesar de que los rasgos mágicos suponen la coincidencia extensional entre una función adaptativa y otra de reconocimiento sexual. El concepto de rasgo mágico es un concepto poblacional que implica simultáneamente pleiotropía ecológico/sexual y selección divergente. La entidad de un rasgo mágico no es individual como debería presuponer el EBI. Si lo fuera entonces la pleiotropía ecológico/sexual determinaría por sí misma la identidad de los individuos y tendría justificación la tesis esencialista según la cual los individuos pertenecen necesariamente a su taxón.

\section{Referencias bibliográficas}

Bolnick, D., Fitzpatrick, B. (2007). Sympatric speciation: models and empirical evidence. Annual Review of Ecology, Evolution, and Systematics, 38(1): 459-487. doi: https://doi. org/10.1146/annurev.ecolsys.38.091206.095804

Blount, Z. D., Lenski, R. E., Losos, J. B. (2018). Contingency and determinism in evolution: Replaying life's tape. Science, 362(6415): eaam5979. doi: 10.1126/science.aam5979

Desjardins, E. (2011). Historicity and experimental evolution. Biology \& Philosophy, 26(3): 339364. doi: https://doi.org/10.1007/s10539-011-9256-4

Devitt, M. (2008). Resurrecting biological essentialism. Philosophy of Science, 75: 344-382. doi: https://doi.org/10.1086/593566

Revista de Humanidades de Valparaíso, 2019, No 14, 75-89

(c) $(1)(9)$ CC BY-NC-ND 
Códigos de barras y esencias históricas: una crítica a la versión moderada del esencialismo biológico intrínseco Julio Torres Meléndez

Devitt, M. (2018a). Individual essentialism in biology. Biology \& Philosophy, 33(5-6): 39. doi: https://doi.org/10.1007/s10539-018-9651-1

Devitt, M. (2018b). Historical biological essentialism. Studies in History and Philosophy of Biological and Biomedical Sciences, 71:1-7. doi: https://doi.org/10.1016/j. shpsc.2018.05.004

Dumsday, T. (2017). Transhumanism, theological anthropology, and modern biological taxonomy. Zygon ${ }^{\circledR}, 52:$ 601-622. doi:10.1111/zygo.12346

Dumsday, T. (2012). A new argument for intrinsic biological essentialism. Philosophical Quarterly, 62: 486-504. doi: https://doi.org/10.1111/j.1467-9213.2012.00048.x

Ereshefsky, M. (2014). Species, historicity, and path dependency. Philosophy of Science, 81(5): 714-726. doi: $10.1086 / 677202$

Ereshefsky, M. (2010b). What's wrong with the new biological essentialism. Philosophy of Science, 77: 674-685. doi: 10.1086/656545

García-Carpintero, M. (1996). Superveniencia y determinación del contenido amplio. Revista de Filosofia, IX(16): 57-92.

Gavrilets, S. (2004). Fitness landscapes and the origin of species. Princeton: Princeton University Press.

Godfrey-Smith, P. (2009). Darwinian Populations and Natural Selection. Oxford: University Press.

Gould, S.J. (2004 [2002]). La estructura de la teoría de la evolución. Traducción de Ambrosio García Leal. Barcelona: Tusquets.

Hebert, P.D.N., Stoeckle, M., Zemlak, T., Francis, C. (2004). Identification of birds through DNA barcodes. PLoS Biol, 2(10): e312. doi: doi.org/10.1371/journal.pbio.0020312

Hebert, P.D.N., Hollingsworth, P.M, Hajibabaei, M. (2016). From writing to reading the encyclopedia of life. Phil. Trans. R. Soc. B, 371(1702): 20150321. doi: 10.1098/ rstb.2015.0321

Holmes, B. (2004). Barcode me. NewScientist, 182: 32-35.

Jones, G., Van Parijs, S. (1993). Bimodal echolocation in pipistrelle bats: are cryptic species present? Proc. R. Soc. Lond. Ser. B, 251: 119-125. doi: https://doi.org/10.1098/rspb.1993.0017

Kekkonen, M., Hebert, P. D. (2014). DNA barcode-based delineation of putative species: efficient start for taxonomic workflows. Mol Ecol Resour, 14: 706-715. doi:10.1111/17550998.12233

Kim, J. (1993). Supervenience as a philosophical concept. En Supervenience and Mind, pp. 131160. Cambridge: Cambridge University Press.

Kingston, T., Rossiter, S. (2004). Harmonic hopping in Wallacea's bats. Nature, 429(6992): 654657. doi: $10.1038 /$ nature 02487

Revista de Humanidades de Valparaíso, 2019, No 14, 75-89

(c) $(1)(9)$ CC BY-NC-ND 
Códigos de barras y esencias históricas: una crítica a la versión moderada del esencialismo biológico intrínseco Julio Torres Meléndez

Kitcher P. (2003 [1984]). Species. En P. Kitcher, Mendel's mirror: philosophical reflections on biology, pp. 113-134. New York: Oxford University Press.

Lee, M. (2004). The molecularisation of taxonomy. Invertebrate Systematics, 18(1): 1-6. doi: doi. org/10.1071/IS03021

Lenski, R., Travisano M. (1994). Dynamics of adaptation and diversification: a 10,000-generation experiment with bacterial populations. Proc Natl Acad Sci U S A, 91(15): 6808-14. doi: 10.1073/pnas.91.15.6808

Maynard Smith, J., Szathmary, E. (1995). The major transitions in evolution. Oxford: University Press.

Mayr, E. (1968 [1966]). Especies animales y evolución. Santiago de Chile-Barcelona: Universidad de Chile y Ariel.

Nosil, P. (2012). Ecological Speciation. Oxford University Press, Oxford.

Okasha, S. (2002). Darwinian Metaphysics: Species and The Question of Essentialism. Synthese, 131: 191-213. doi: 10.1023/A:1015731831011

Paz,A., González, M., Andrew, J. (2011). Códigos de barras de la vida: introducción y perspectivas. Acta biol. Colom., 16(3): 161-176.

Rubinoff, D., Cameron, S., Will, K. (2006). Are plant DNA barcodes a search for the Holy Grail? Trends in Ecology and Evolution, 21(1): P1-2. doi: 10.1016/j.tree.2005.10.019

Servedio, M.R, Van Doorn, G. S., Kopp, M., Frame, A. M., Nosil, P. (2011). Magic traits in speciation: 'magic' but not rare? Trends. Ecol. Evol., 26(8): 389-397. doi: 10.1016/j. tree.2011.04.005

Sober, E. (1980). Evolution, Population Thinking, and Essentialism. Philosophy of Science, 47: 350-383. doi: https://doi.org/10.1086/288942

Soler, M. (2003). Selección natural y adaptación. En M. Soler (ed.), Evolución. La base de la biología, pp. 127-157. Granada: Proyecto Sur de Ediciones.

Tahko, T. (2015). Natural Kind Essentialism Revisited. Mind, 124(495): 475-822. doi: 10.1093/ $\mathrm{mind} / \mathrm{fzv} 027$

Veit, W. (2019). Evolution of multicellularity: cheating done right. Biology \& Philosophy, 34(3): 34. doi: https://doi.org/10.1007/s10539-019-9688-9

Walsh, D. (2006). Evolutionary Essentialism. The British Journal for the Philosophy of Science, 57(2): 425-448. doi: https://doi.org/10.1093/bjps/ax1001

Will, K.W., Mishler, B.D., Wheeler, Q.D. (2005). The perils of DNA barcoding and the need for integrative taxonomy. Syst Biol., 54(5): 844-51. doi: 10.1080/10635150500354878

Revista de Humanidades de Valparaíso, 2019, No 14, 75-89

(c) $(1)(9)$ CC BY-NC-ND 